\title{
Influência da densidade do solo no desenvolvimento inicial do pinhão-manso cultivado em Latossolo Vermelho eutroférrico
}

\author{
Tatiane Ohland ${ }^{1}$, Maria do Carmo Lana ${ }^{2}$, Jucenei Fernando Frandoloso ${ }^{3}$, Leandro Rampim ${ }^{4}$, \\ Jaqueline Regina Bergmann ${ }^{5}$, Danielle Tesche Cabreira ${ }^{6}$ \\ http://dx.doi.org/10.1590/0034-737X201461050004
}

\begin{abstract}
RESUMO
Este trabalho teve por objetivo avaliar a influência da densidade do solo no desenvolvimento inicial da cultura do pinhão-manso. O experimento foi realizado em vasos de $10,6 \mathrm{dm}^{3}$, em casa de vegetação. O solo utilizado foi o Latossolo Vermelho eutroférrico de textura argilosa, coletado em Marechal Cândido Rondon - PR. O delineamento experimental utilizado foi o de blocos casualizados, composto por cinco níveis de densidade do solo $(1,08 ; 1,22$;

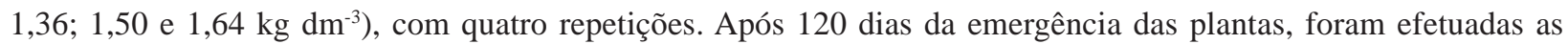
avaliações biométricas e as relativas ao do tecido vegetal. Houve redução de $25 \%$ da altura das plantas, na densidade de $1,64 \mathrm{~kg} \mathrm{dm}^{-3}$, quando,comparada com a da densidade de $1,08 \mathrm{~kg} \mathrm{dm}^{-3}$. Para o comprimento radicular, a redução foi de aproximadamente $24,35,54$ e $66 \%$ para as densidades de 1,22;1,36; 1,50 e 1,64 kg dm ${ }^{-3}$ respectivamente, quando comparadas com o da densidade de $1,08 \mathrm{~kg} \mathrm{dm}^{-3}$. A limitação do desenvolvimento da parte aérea ocorreu a partir da densidade estimada de $1,26 \mathrm{~kg} \mathrm{dm}^{-3}$, com redução do número de folhas, da área foliar e da produção de matéria seca da parte aérea. O desenvolvimento do sistema radicular e o conteúdo de $\mathrm{P}$ e K nas plantas de pinhãomanso reduziram-se linearmente com o aumento da densidade do solo.
\end{abstract}

Palavras-chave: Jatropha curcas L., compactação do solo, resistência à penetração.

\begin{abstract}
Influence of soil density on the early growth of Jatrophacurcas L. cultivated in Oxisol

The objective of this work was to evaluate theinfluence of soil densities on the early growth ofthephysic nut(JatrophacurcasL.). The experiment wascarried out in $10.6 \mathrm{dm}^{3}$ pots in a greenhouse. The soilused in the experiment wasa clay-texture Oxisolcollected in Marechal Cândido Rondon, Paraná State, Brazil. The experimental designwas randomized blockswith five levels ofsoil density $\left(1.08,1.22,1.36,1.50\right.$ and $\left.1.64 \mathrm{~kg} \mathrm{dm}^{-3}\right)$ with four repetitions. Biometric and plant tissue evaluations were performed 120 days after plant emergence.It was found a reduction by $25 \%$ in plant heightat a density of $1.64 \mathrm{~kg} \mathrm{dm}^{-3} \mathrm{when}$ compared todensity of $1.08 \mathrm{~kg} \mathrm{dm}^{-3}$. For root length, the reduction was approximately $24 \%, 35 \%, 54 \%$ and $66 \%$ at the densities of $1.22,1.36,1.50$ and $1.64 \mathrm{~kg} \mathrm{dm}^{-3}$,
\end{abstract}

\footnotetext{
Recebido para publicação em 20/06/2013 e aprovado em 20/02/2014.

Engenheira-agrônoma, Mestra. Universidade Estadual do Oeste do Paraná, Rua Pernambuco, 91, Caixa Postal 1008, Centro, 85960-000, Marechal Cândido Rondon, Paraná. tatianeohland @hotmail.com (autora para correspondência).

${ }^{2}$ Engenheira-agrônoma, Doutora. Universidade Estadual do Oeste do Paraná, Rua Pernambuco, 91, Caixa Postal 1008, Centro, 85960-000, Marechal Cândido Rondon, Paraná. maria.lana@unioeste.br

${ }_{3}^{3}$ Engenheiro-agrônomo, Doutor. Universidade Estadual do Oeste do Paraná, Rua Pernambuco, 91, Caixa Postal 1008, Centro, 85960-000, Marechal Cândido Rondon, Paraná. juceneiff@hotmail.com

${ }^{4}$ Engenheiro-agrônomo, Mestre. Universidade Estadual do Oeste do Paraná, Rua Pernambuco, 91, Caixa Postal 1008, Centro, 85960-000, Marechal Cândido Rondon, Paraná. rampimleandro@yahoo.com.br

${ }^{5}$ Graduanda em zootecnia. Universidade Estadual do Oeste do Paraná, Rua Pernambuco, 91, Caixa Postal 1008, Centro, 85960-000, Marechal Cândido Rondon, Paraná. bergmannjaque@ hotmail.com

${ }^{6}$ Graduanda em zootecnia. Universidade Estadual do Oeste do Paraná, Rua Pernambuco, 91, Caixa Postal 91, Centro, 85960-000, Marechal Cândido Rondon, Paraná. danielle_tesche@hotmail.com
} 
respectively, when compared with density of $1.08 \mathrm{~kg} \mathrm{dm}^{-3}$. Limitation of shoot development was found from the estimated density of $1.26 \mathrm{~kg} \mathrm{dm}^{-3}$, with a reduction in the number of leaves, leaf area and dry weight of shoots. The root system development and content of $\mathrm{P}$ and $\mathrm{K}$ in plants of physic nut decreased linearly as the density increased.

Key words:Jatropha curcas L.,penetration resistance,soil compaction.

\section{INTRODUÇÃO}

O pinhão-manso (Jatropha curcas L.) é uma espécie oleaginosa, considerada como alternativa para a produção de biodiesel (Arruda et al., 2004). O teor de óleo em suas sementes varia entre 30 e $40 \%$, com produção anual de 1.100 e $1.700 \mathrm{~L} \mathrm{ha}^{-1}$ (Nunes, 2007). Assim, com a possibilidade do uso do óleo do pinhão-manso para a produção do biodiesel, abrem-se perspectivas para o crescimento das áreas de plantio dessa oleaginosa.

O pinhão-manso é originário da América Central, sendo encontrado em diversas regiões do Brasil (Beltrão, 2005). Trata-se de uma espécie perene e monoica, pertencente à família das Euforbiáceas. É um arbusto de crescimento rápido, caducifólio, cuja altura média atinge de dois a três metros, podendo alcançar até cinco metros (Arruda et al., 2004; Saturnino et al., 2005).

Para Laviola \& Dias (2008), os resultados de pesquisas com a cultura do pinhão-manso são ainda incipientes e preliminares. Ainda assim, observa-se expansão da área cultivada com essa espécie. Sabe-se, no entanto que, para se obter alta produtividade de frutos são necessários boa disponibilidade de água, solos férteis e boas condições físicas.

As propriedades físicas do solo são alteradas principalmente pelas condições de manejo, sendo o revolvimento ou a compactação as principais formas de se alterar sua estrutura, refletindo-se em modificações na sua densidade (Silva et al., 2004).

Propriedades como a densidade, a porosidade, o teor de umidade e a taxa de infiltração de água estão intimamente associadas à estrutura e à textura do solo e podem tanto estimular como inibir o desenvolvimento das plantas (Meurer, 2007).

Como o crescimento de raízes ocorre no espaço poroso do solo, pode ser reduzido ou inexistente com o aumento da densidade, resultando no aumento da resistência à penetração das raízes (Bonfim-Silva et al., 2011).

De acordo com Secco et al. (2004), os valores de resistência do solo de até 2,60 $\mathrm{MPa}$ e densidade $1,51 \mathrm{~kg}$ $\mathrm{dm}^{-3}$, em Latossolo Vermelho distroférrico, na camada até $0,20 \mathrm{~m}$, não comprometeram o rendimento de grãos de soja, em condições de campo. Silva et al. (2002) ve- rificaram, em Latossolo Vermelho argiloso e em Latossolo Vermelho-Amarelo franco-arenoso, que a compactação restringe o crescimento e aumenta o diâmetro médio de raízes de eucalipto, bem como reduz o acúmulo de $\mathrm{K}$ na planta.

Para Materechera et al. (1992), a resistência mecânica do solo causa aumento do diâmetro das raízes na camada compactada, por provocar modificações morfológicas e fisiológicas, próprias de cada espécie.

$\mathrm{O}$ aumento da densidade afeta a velocidade de infiltração da água no solo e a absorção de nutrientes pela cultura da mamoneira (Costa et al., 2010). No entanto, Vale et al., (2006) verificaram redução do desenvolvimento do pinhão-manso submetido aos diferentes níveis de densidade em solo arenoso.

Além dos efeitos da densidade sobre o desenvolvimento das plantas, ainda se verifica sua interferência na absorção de nutrientes. Como a compactação tem efeito negativo na porosidade, a disponibilidade de nutrientes para as plantas será afetada, visto que interfere nos mecanismos de fluxo de massa e difusão, que são responsáveis pelo transporte de nutrientes até as raízes. Ou seja, são processos dependentes da estrutura do solo. Além de alterar os mecanismos pelos quais os nutrientes são transportados no solo, a compactação também pode afetar a quantidade de nutrientes disponíveis (Medeiros et al., 2005).

A compactação aumenta a interação dos íons de fosfato e de potássio com a superfície dos coloides, ao longo de sua trajetória de difusão, fazendo com que estes elementos tenham que se difundir cada vez mais próximo da superfície que os adsorve (Novais \& Smyth, 1999).

O aumento da densidade do solo promoveu redução da concentração de fósforo no tecido vegetal para a cultura do feijoeiro (Alves et al., 2003), e de fósforo e potássio, para a cultura do arroz (Medeiros et al., 2005).

Considerando-se a diversidade dos solos brasileiros, ressalta-se a importância da realização de estudos quanto ao desenvolvimento da cultura do pinhão-manso em diferentes classes e densidades de solo. Assim, este trabalho teve por objetivo avaliar a influência da densidade do solo no desenvolvimento inicial da cultura do pinhão-manso cultivado em Latossolo Vermelho eutroférrico. 


\section{MATERIAL E MÉTODOS}

Este experimento foi desenvolvido em casa de vegetação localizada nas dependências do Centro de Controle Biológico e Cultivo Protegido Prof. Dr. Mário Cezar Lopes, pertencente ao Núcleo de Estações Experimentais do Centro de Ciências Agrárias da UNIOESTE, no município de Marechal Cândido Rondon, PR. O solo utilizado foi coletado em Marechal Cândido Rondon, PR, o qual foi destorroado e peneirado, sendo classificado como Latossolo Vermelho eutroférrico (Embrapa, 2006), com $576 \mathrm{~g} \mathrm{~kg}^{-1}$ de argila, $401 \mathrm{~g} \mathrm{~kg}^{-1}$ de silte e 23 $\mathrm{g} \mathrm{kg}^{-1}$ de areia, com densidade natural de $1,38 \mathrm{~kg} \mathrm{dm}^{-3}$. O solo apresentou a seguinte caracterização química: $\mathrm{pH}$ : 5,5; P: 7,7 mg dm${ }^{-3}$; K: 0,4 $\mathrm{cmol}_{\mathrm{c}} \mathrm{dm}^{-3}$; $\mathrm{Mg}: 1,9 \mathrm{cmol}_{\mathrm{c}}$ $\mathrm{dm}^{-3}$; Ca: 4,1 $\mathrm{cmol}_{\mathrm{c}} \mathrm{dm}^{-3}$; Al: $0,0 \mathrm{cmol}_{\mathrm{c}} \mathrm{dm}^{-3} ; \mathrm{H}+\mathrm{Al}: 2,8$ cmol $\mathrm{dm}^{-3}$; CTC: $9,2 \mathrm{cmol}_{\mathrm{c}} \mathrm{dm}^{-3}$; SB: $6,3 \mathrm{cmol}_{\mathrm{c}} \mathrm{dm}^{-3}$; V: 69,1\%; MO: 8,9 $\mathrm{g} \mathrm{dm}^{-3}$; Zn: 2,6 $\mathrm{mg} \mathrm{dm}^{-3}$; Mn: 68,0 mg $\mathrm{dm}^{-3}$; Fe: 78,0 mg dm${ }^{-3}$; Cu: 10,7 $\mathrm{mg} \mathrm{dm}^{-3}$.

O delineamento experimental utilizado foi o de blocos casualizados, com quatro repetições. As colunas de solo, com $60 \mathrm{~cm}$ de altura, foram montadas em tubos de PVC com $15 \mathrm{~cm}$ de diâmetro (volume de 10,6 dm $\mathrm{dm}^{3}$ ), fechadas na base com tampa de PVC com quatro furos. As colunas foram preenchidas com a quantidade de solo correspondente às densidades de 1,$08 ; 1,22 ; 1,36 ; 1,50 \mathrm{e}$ $1,64 \mathrm{~kg} \mathrm{dm}^{-3}$. A densidade do solo foi definida por meio de ensaio preliminar, no qual o solo correspondente às diferentes densidades foi umedecido $(65 \%$ da máxima capacidade de retenção de água e teor de umidade de $20 \%$ ) e compactado nos vasos por meio de golpes com um cilindro de ferro (massa: $11 \mathrm{~kg}$ ), sendo os golpes de cada tratamento contabilizados e realizados a uma altura de $10 \mathrm{~cm}$ da amostra de solo.

A determinação da densidade no ensaio preliminar foi realizada pelo método do anel volumétrico (Embrapa, 1997); esse anel, de volume conhecido, foi colocado dentro da massa de solo a ser compactada. A resistência mecânica à penetração foi estimada a partir das leituras de penetrômetro de impacto, até à profundidade de 20 $\mathrm{cm}$, por meio da fórmula utilizada por Stolf (1991) : $\operatorname{RMSP}=(3,87+9,60 * \mathrm{~N}) /$ 0,098. Onde: RMSP $=\mathrm{Re}-$ sistência mecânica do solo à penetração, em $\mathrm{MPa} ; \mathrm{N}=$ Número de impactos por decímetro de profundidade. Os resultados de resistência mecânica do solo à penetração foram de 1,$40 ; 2,26 ; 2,77 ; 3,59$ e 4,02 MPa, correspondentes às densidades do solo de 1,$08 ; 1,22 ; 1,36 ; 1,50 \mathrm{e}$ $1,64 \mathrm{~kg} \mathrm{dm}^{-3}$, respectivamente.

A semeadura do pinhão-manso foi realizada em quatro de janeiro de 2011, com quatro sementes por vaso e desbaste após dez dias da emergência, deixando-se apenas uma planta por vaso. As sementes de pinhão-manso foram provenientes do município de Dourados, MS, de uma área experimental do Centro de Pesquisas Agropecuária Oeste (CPAO), da Empresa Brasileira de Pesquisa Agropecuária (Embrapa). A adubação foi realizada com $170 \mathrm{mg} \mathrm{dm}^{-3}$ de $\mathrm{N}$ (ureia), $296 \mathrm{mg} \mathrm{dm}^{-3}$ de $\mathrm{P}$ (superfosfato simples) e $200 \mathrm{mg} \mathrm{dm}^{-3}$ de $\mathrm{K}$ (cloreto de potássio), com base nas recomendações de Dias et al. (2007). Realizaram-se duas adubações nitrogenadas de cobertura, aos 45 e 90 dias após a emergência, utilizando-se em cada aplicação $100 \mathrm{mg} \mathrm{dm}^{-3}$ de $\mathrm{N}$ (ureia). O fornecimento de água às plantas foi por meio de rega diária, na quantidade de $200 \mathrm{ml}$ por planta.

O controle da ferrugem (Phakospora arthuriana Buriticá \& Hennen) foi realizado com fungicida (tebuconazole - $200 \mathrm{~g} \mathrm{~L}^{-1}$ ), na dose de $0,75 \mathrm{~L} \mathrm{ha}^{-1}$, aos 48, 70 e 95 dias após a emergência. Para controle de ácaros (Polyphagotarsonemus latus Banks), utilizouse acaricida (abamectin - $18 \mathrm{~g} \mathrm{~L}^{-1}$ ), na dose de 1,0 $\mathrm{L} \mathrm{ha}^{-1}$, aos 27, 47, 70 e 100 dias após a emergência. A aplicação foi realizada com pulverizador manual, com capacidade de cinco litros.

Após 120 dias da emergência das plantas, avaliaramse o número de folhas, a altura de planta $(\mathrm{cm})$ desde o colo da planta até a inserção da última folha, com régua, e o diâmetro do caule, mensurado a $7 \mathrm{~cm}$ do colo da planta, com paquímetro digital. Posteriormente, as plantas foram cortadas na altura do colo e a parte aérea separada em caule e folhas. As folhas foram acondicionadas em sacos plásticos para análise da área foliar, com equipamento LI3100C Portable Leaf Area Meter.

Os vasos foram desmontados para a retirada do sistema radicular, mediante lavagem com água corrente, com uso de peneira, sendo avaliado o comprimento da raiz principal, com regra graduada. $\mathrm{O}$ volume radicular foi obtido pelo deslocamento de água, em proveta graduada de um litro.

As partes das plantas (folhas, caule e raízes) foram acondicionadas em sacos de papel, colocadas em estufa, com circulação forçada de ar, a $65^{\circ} \mathrm{C}$, para secagem até peso constante e posterior quantificação de produção de matéria seca, utilizando-se balança de precisão. A relação raiz/parte aérea foi obtida pela razão entre a produção de matéria seca de raízes e a produção de matéria seca de folhas + caule. A densidade de raízes representa a razão entre a produção de matéria seca de raízes e o volume radicular.

Para a determinação de fósforo $(\mathrm{P})$, potássio $(\mathrm{K})$, cálcio $(\mathrm{Ca})$ e magnésio $(\mathrm{Mg})$ foram utilizadas amostras do material coletado para a avaliação da produção de matéria seca, as quais foram moídas em moinho tipo Willye. Amostras de 0,2 gramas de tecido vegetal (folhas+pecíolos, caule e raízes) foram mineralizadas por digestão nítricoperclórica na proporção de 3:1. Nos extratos, o P foi determinado pelo método do ácido ascórbico, modificado por Braga \& Defelipo (1974); o K, por fotometria 
de emissão de chama; o Ca e o Mg por espectrofotometria de absorção atômica.

Os resultados obtidos foram submetidos à análise de variância e análise de regressão, com o programa estatístico SISVAR (Ferreira, 2000).

\section{RESULTADOS E DISCUSSÃO}

O aumento da densidade do solo, de 1,08 a 1,64 kg $\mathrm{dm}^{-3}$, influenciou as variáveis número de folhas, área foliar e altura de plantas. Observa-se, para as variáveis número de folhas (Figura 1A) e área foliar (Figura 1B), efeito quadrático com o aumento da densidade do solo, até a densidade de $1,26 \mathrm{~kg} \mathrm{dm}^{-3}$, para o número máximo de folhas (33 folhas/planta) e, também, para o máximo de área foliar $\left(2181,52 \mathrm{~cm}^{2}\right)$.

Bonfim-Silva et al. (2011) observaram efeito semelhante para o número de folhas e também para o número de perfilhos em plantas de trigo, sendo que as maiores produções foram observadas nos tratamentos 1,35 e 1,32 $\mathrm{kg} \mathrm{dm}^{-3}$, respectivamente. Segundo os autores, esses níveis de compactação contribuíram para que os nutrientes do solo permanecessem ao alcance e disponíveis para as raízes da cultura.

A compactação reduz a porosidade e a aeração do solo, aumentando a densidade e a resistência do solo à penetração, afetando o desenvolvimento radicular e aéreo da planta. No entanto, a baixa densidade pode ser
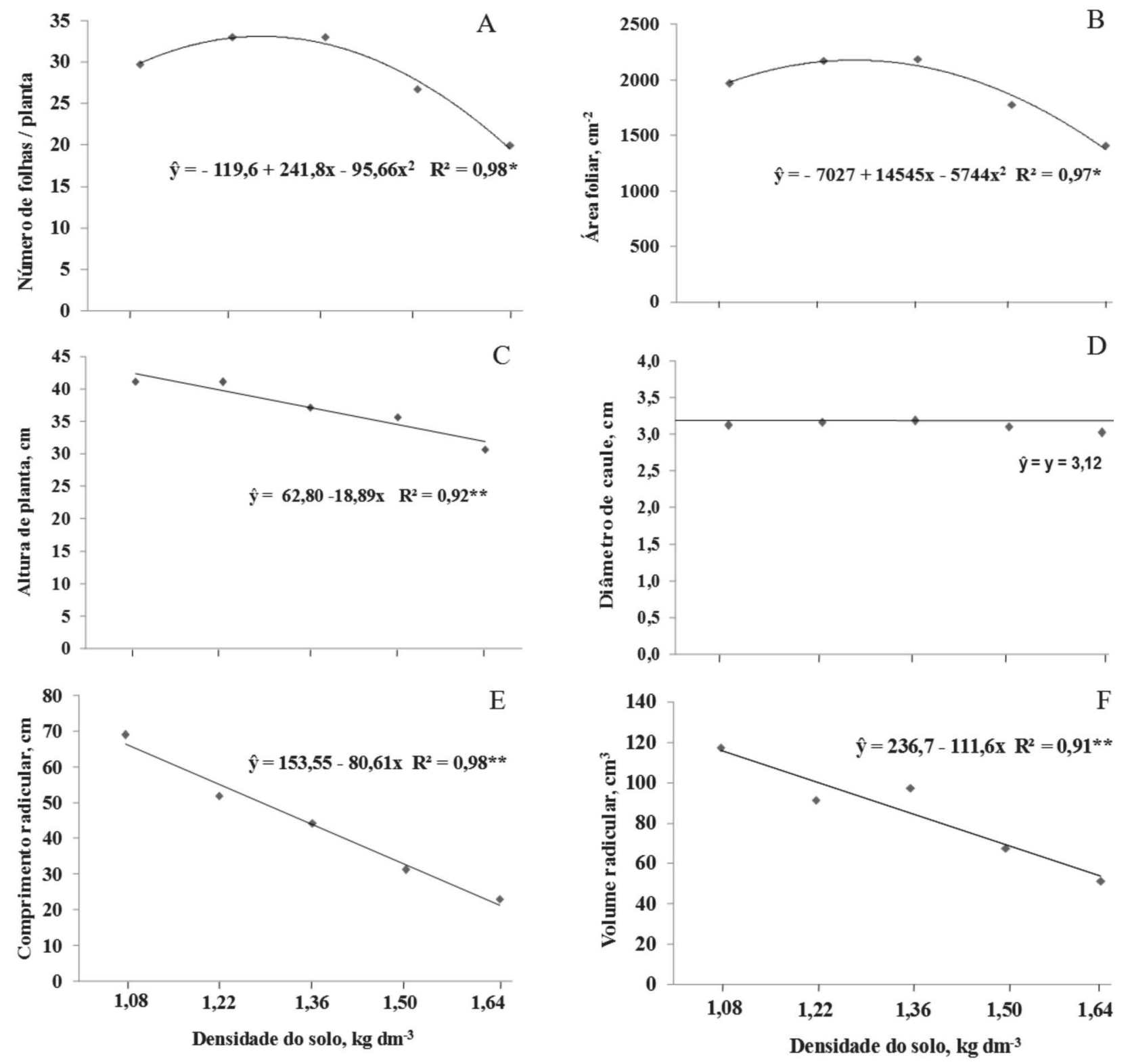

Figura 1. Número de folhas/planta (A), área foliar (B) altura de plantas (C), diâmetro de caule (D), comprimento radicular (E) e volume radicular $(\mathrm{F})$ de pinhão-manso em razão do aumento da densidade de solo (* significativo a $5 \%$ de probabilidade, ** significativo a $1 \%$ de probabilidade). 
indicativa de um solo desagregado, que vem comprometer a retenção de água (Suzuki et al., 2007).

A resistência à penetração aumenta com a elevação da densidade do solo, sendo restritiva ao crescimento radicular, acima de certos valores, que variam de 1,5 a 4,0 $\mathrm{MPa}$, dependendo da espécie. Resistências à penetração em torno de 3,5 a 6,5 MPa, aparentemente, são as mais adequadas para se considerar que um solo está com possíveis problemas de impedimento mecânico (Silva et al., 2004). Neste trabalho, foram obtidos valores de resistência à penetração dentro desta faixa de restrição ao crescimento radicular.

A tendência linear decrescente, demonstrada na variável altura de plantas, ressalta o efeito significativo da densidade do solo no desenvolvimento da cultura do pinhãomanso. Houve redução de aproximadamente $25 \%$ da altura das plantas, na densidade de $1,64 \mathrm{~kg} \mathrm{dm}^{-3}$, quando comparado com a densidade de $1,08 \mathrm{~kg} \mathrm{dm}^{-3}$ (Figura 1C).

Para Mapfumo et al. (1998), a redução do crescimento das plantas em solos compactados é resultante da combinação do aumento da resistência à penetração de raízes, à deficiência de oxigênio e a alterações no ambiente da rizosfera, que afetam a disponibilidade de nutrientes para as plantas.

Abreu et al. (2006), avaliando plantas de pinhão-manso sob diferentes níveis de compactação do solo, concluíram que a espécie é sensível à compactação, sendo, portanto, necessário o prévio preparo em áreas com essas condições. Castro et al. (2011) também concluíram a sensibilidade dessa espécie à compactação, em condições de campo, no cultivo integrado com pecuária de corte.

O diâmetro de caule não foi influenciado pelas densidades do solo, apresentando média de 3,12 cm (Figura 1D). Os resultados deste estudo corroboram os de Silva et al. (2012). Esses autores verificaram que o diâmetro de caule de plantas de pinhão-manso não apresentou alterações significativas, em decorrência do aumento da densidade do solo de 1,14 a 1,58 $\mathrm{kg} \mathrm{dm}^{-3}$, em Latossolo Vermelho de textura média.

No entanto, Vale et al. (2006), também avaliando o diâmetro de plantas de pinhão-manso, verificaram uma redução do crescimento, à medida que se aumentava a compactação do solo. Neste trabalho, apesar de não significativo o ajuste do modelo linear, observa-se uma tendência de redução do diâmetro caulinar nas densidades de 1,50 e $1,64 \mathrm{~kg} \mathrm{dm}^{-3}$.

$\mathrm{O}$ aumento da densidade do solo afetou o comprimento e o volume radicular, a produção de matéria seca de caule, raízes e planta inteira, a relação raiz/parte aérea e a densidade de raízes, com exceção da produção de matéria seca de folhas.

O comprimento e o volume radicular, a produção de matéria seca de raiz e a relação raiz/parte aérea apresen- taram comportamento linear, decrescendo com o aumento da densidade do solo (Figura 1E e 1F; Figura 2C e 2E).

Observou-se redução de aproximadamente 24, 35 , 54 e $66 \%$ do comprimento radicular nas densidade de 1,$22 ; 1,36 ; 1,50$ e $1,64 \mathrm{~kg} \mathrm{dm}^{-3}$, respectivamente, em relação ao mesmo parâmetro na densidade de $1,08 \mathrm{~kg} \mathrm{dm}^{-3}$ (Figura 1E).

O volume radicular foi severamente afetado pelo aumento da densidade do solo. Houve redução de 22, 17 , 42 e $56 \%$ para as densidades de solo de 1,$22 ; 1,36 ; 1,50$ e $1,64 \mathrm{~kg} \mathrm{dm}^{-3}$, respectivamente, em relação ao mesmo parâmetro na densidade de $1,08 \mathrm{~kg} \mathrm{dm}^{-3}$ (Figura 1F). O decréscimo da relação raiz/parte aérea com o aumento da densidade do solo indica que o menor crescimento radicular afetou o crescimento da parte aérea.

A produção de matéria seca de caule e a matéria seca total apresentaram resposta polinomial de segunda ordem (Figura 2B e 2D). Verificou-se que, na densidade na $1,22 \mathrm{~kg} \mathrm{dm}^{-3}$, obteve-se maior produção de matéria seca de caule $(47,37 \mathrm{~g})$. Para a matéria seca total, observou-se maior produção de matéria seca $(87,08 \mathrm{~g})$ na densidade de $1,08 \mathrm{~kg} \mathrm{dm}^{-3}$.

A densidade de raízes, razão entre a matéria seca de raízes e volume radicular, aumentou linearmente com a densidade do solo (Figura 2F). Observou-se que, na densidade de $1,08 \mathrm{~kg} \mathrm{dm}^{-3}$ as raízes não apresentavam alterações na morfologia, ou seja, raízes curtas, grossas e escamosas. Nas densidades de 1,22 e 1,36 kg dm ${ }^{-3}$, o crescimento do sistema radicular em profundidade foi moderadamente afetado. Já as densidades de 1,50 e 1,64 $\mathrm{kg} \mathrm{dm}^{-3}$ foram consideradas as mais críticas para o crescimento das plantas de pinhão-manso, o sistema radicular teve dificuldade de se desenvolver e a raiz pivotante foi impedida de crescer. Assim, o sistema radicular tornou-se mais superficial com o aumento da densidade do solo.

Segundo Silva et al. (1992), o tipo de raiz é importante no processo de exploração do solo compactado, sendo que as pivotantes, de grande diâmetro, são menos eficientes na penetração em solos com alta densidade, em relação a raízes secundárias, de menor diâmetro.

Abreu et al. (2006) não encontraram efeito significativo do aumento da densidade do solo, de 1,34 a 1,81 kg $\mathrm{dm}^{-3}$, sobre a produção de matéria seca da parte aérea de plantas de pinhão-manso, após 37 dias do plantio, porém o crescimento radicular foi reduzido linearmente com o aumento da densidade do solo em subsuperfície.

$\mathrm{Na}$ aveia branca, o aumento da densidade do solo proporciona redução da matéria seca da parte aérea, sendo significativamente menor na densidade $1,70 \mathrm{~kg} \mathrm{dm}^{-3}$ (Müller et al., 2001). Na cultura do eucalipto, a produção de matéria seca foi negativamente afetada pelo aumento da compactação para os valores de densidade do solo de 0,91 a 1,30 kg dm${ }^{-3}$, em Latossolo Vermelho (Silva, 2000). 
Ribeiro et al. (2010) observaram que o aumento da densidade do solo, de 0,90 a 1,30 $\mathrm{kg} \mathrm{dm}^{-3}$, em Latossolo Vermelho (LV) muito argiloso, e de 1,30 a 1,70 $\mathrm{kg} \mathrm{dm}^{-3}$, em Latossolo Vermelho-Amarelo (LVA) de textura média, proporcionaram efeito depressivo no crescimento da soja e do eucalipto. A redução observada na parte aérea da soja foi de $50 \%$, no solo LV, e $26 \%$ no LVA; para o eucalipto, esses valores foram de 52 e $32 \%$, respectivamente.

Para Tavares Filho et al. (1999), a estrutura do solo pode ser modificada em função da elevação de sua densidade, sendo que os macroagregados são destruídos e o solo apresenta estrutura degradada, podendo impedir o crescimento de raízes e diminuir o volume de solo explorado pelo sistema radicular. Isso implica a redução do desenvolvimento da planta, o que foi observado na avaliação da produção de matéria seca.

A
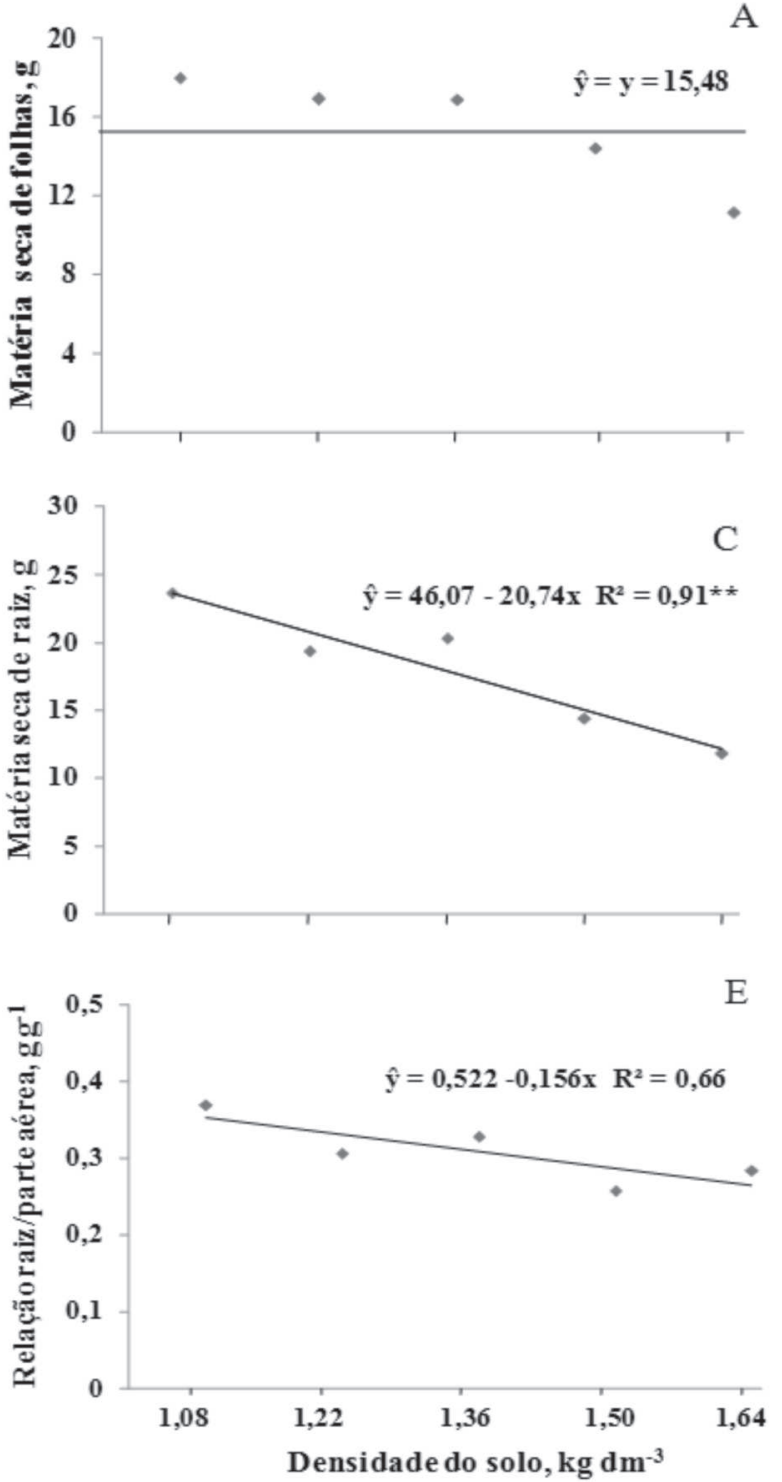

Houve redução linear para conteúdo de $\mathrm{P}$ nas folhas e raízes e de $\mathrm{K}$ nas raízes, com o aumento da densidade do solo (Tabela 1 e Figura 3). De acordo com Meurer (2006), estes nutrientes (P e K) são transportados da solução do solo até a superfície radicular principalmente pelo mecanismo de difusão. A absorção desses nutrientes pelas plantas cria uma zona de depleção em torno das raízes e, se a difusão é dificultada, não há reposição desses nutrientes na zona de absorção, refletindo-se em menor absorção (Raij, 2011).

O fluxo difusivo de K no solo é influenciado pela umidade e pela compactação, aumentando com o acréscimo do conteúdo de água e apresentando valores mais baixos na condição de solo com elevada densidade (Costa et al., 2009). Outro fator de fundamental importância na absorção de $\mathrm{P}$ e $\mathrm{K}$ é a extensão do
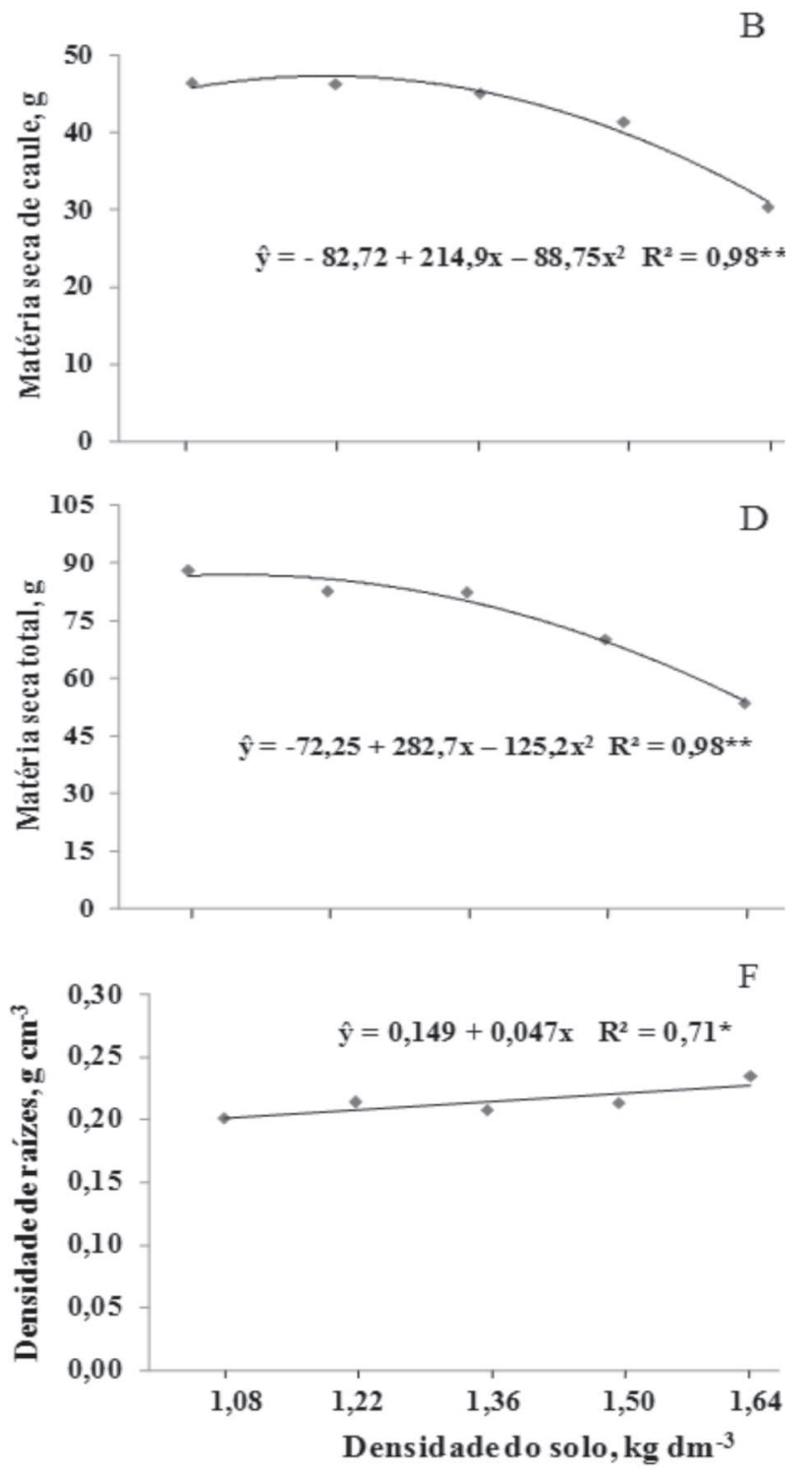

Figura 2. Produção de matéria seca de folhas (A) de caule (B), de raiz (C), produção de matéria seca total de planta (D), relação raiz/ parte aérea (E) e densidade de raízes (F) de pinhão-manso em razão do aumento da densidade de solo (** significativo a $1 \%$ de probabilidade, ${ }^{*}$ significativo a $5 \%$ de probabilidade). 
Tabela 1. Resumo da análise de variância para conteúdo de fósforo $(\mathrm{P})$, potássio $(\mathrm{K})$, cálcio $(\mathrm{Ca})$ e magnésio $(\mathrm{Mg})$ nas folhas, no caule e nas raízes de pinhão-manso

\begin{tabular}{|c|c|c|c|c|c|c|}
\hline \multirow{3}{*}{ FV } & \multicolumn{3}{|c|}{$\mathbf{P}$} & \multicolumn{3}{|c|}{$\mathbf{K}$} \\
\hline & Folhas & Caule & Raízes & Folhas & Caule & Raízes \\
\hline & \multicolumn{6}{|c|}{ Quadrados médios } \\
\hline Bloco & $36,16^{\mathrm{ns}}$ & $10,69^{\text {ns }}$ & $2,23^{\mathrm{ns}}$ & $2368,02^{\text {ns }}$ & $47429,82^{\text {ns }}$ & $257,16^{\mathrm{ns}}$ \\
\hline Densidade do solo & $172,22^{*}$ & $139,76^{\mathrm{ns}}$ & $91,81^{* *}$ & $17197,28^{\mathrm{ns}}$ & $61269,61^{\mathrm{ns}}$ & $41923,71^{* *}$ \\
\hline Erro & 32,98 & 46,25 & 4,84 & 8205,86 & 63556,57 & 1697,57 \\
\hline C.V. $(\%)$ & 21,30 & 17,11 & 12,27 & 35,28 & 36,48 & 12,59 \\
\hline \multirow[t]{2}{*}{ Média (mg/planta) } & 26,96 & 39,74 & 17,93 & 256,75 & 691,13 & 327,34 \\
\hline & \multicolumn{3}{|c|}{$\mathbf{C a}$} & \multicolumn{3}{|c|}{ Mg } \\
\hline \multirow[t]{2}{*}{ FV } & Folhas & Caule & Raízes & Folhas & Caule & Raízes \\
\hline & \multicolumn{6}{|c|}{ Quadrados médios } \\
\hline Bloco & $11237,47^{\mathrm{ns}}$ & $31319,87^{\text {ns }}$ & $55142,33^{\text {ns }}$ & $16,96^{\mathrm{ns}}$ & $8089,32^{\mathrm{ns}}$ & $897,56^{\mathrm{ns}}$ \\
\hline Densidade do solo & $34424,58^{\mathrm{ns}}$ & $158504,70^{\mathrm{ns}}$ & $58446,62^{\mathrm{ns}}$ & $718,54^{\mathrm{ns}}$ & $16888,55^{\mathrm{ns}}$ & $1396,46^{\mathrm{ns}}$ \\
\hline Erro & 23143,10 & 94682,53 & 40005,70 & 501,35 & 5915,11 & 615,13 \\
\hline C.V. (\%) & 22,81 & 37,92 & 53,91 & 24,78 & 44,36 & 35,01 \\
\hline Média (mg/planta) & 666,50 & 811,50 & 371,64 & 90,36 & 173,36 & 70,81 \\
\hline
\end{tabular}

**significativo a $1 \%$ de probabilidade, * significativo a $5 \%$ de probabilidade, ${ }^{\text {ns }}$ não significativo pelo teste $\mathrm{F}$.

Folhas

A
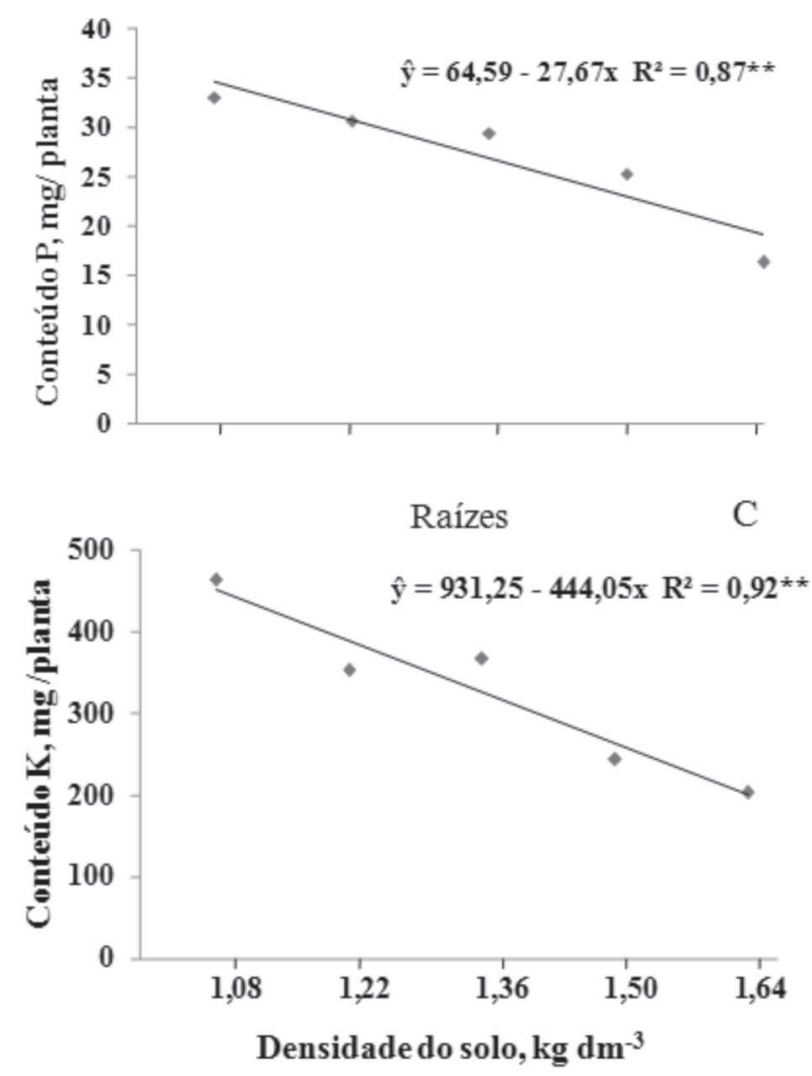

sistema radicular. Os efeitos da carência de P são mais evidentes pela acentuada redução do crescimento da planta como um todo. O baixo suprimento desse nutriente diminui a área foliar, como consequência, principalmente, do menor número de folhas (Araújo \& Machado, 2006).

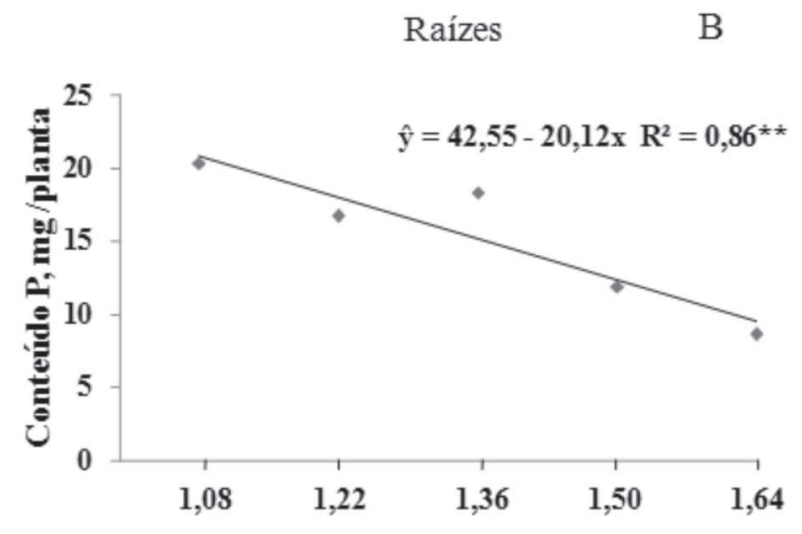

Densidade do solo, $\mathrm{kg} \mathrm{dm}^{-3}$

Figura 3. Conteúdo de fósforo nas folhas (A) e nas raízes (B) potássio nas raízes $(\mathrm{C})$ de plantas pinhão-manso em função de diferentes densidades de solo (** significativo a $1 \%$ de probabilidade).

A compactação aumenta a interação dos íons de fosfato e de potássio com a superfície dos coloides, ao longo de sua trajetória de difusão, fazendo com que estes elementos tenham que se difundir cada vez mais próximo da superfície que os adsorve (Novais \& Smyth, 1999). 
Desta forma, neste trabalho o aumento da densidade do solo provocou menor crescimento do sistema radicular e a redução dos poros do solo, em decorrência da compactação, pode ter afetado o processo de transporte de nutrientes por difusão, resultando em menor absorção de $\mathrm{P}$ e K.

Silva et al. (2002), avaliando solos distintos (Latossolo Vermelho e Latossolo Vermelho-Amarelo) e níveis de compactação, em estudo com plantas de eucalipto, verificaram que o aumento do grau de compactação reduz o crescimento e o acúmulo de K na planta. Na cultura da soja, houve redução do acúmulo de $\mathrm{K}$, quando a densidade do solo aumentou de 1,12 para 1,36 $\mathrm{kg} \mathrm{dm}^{-3}$ (Silva \& Rosolem, 2001).

Estudos indicam que o pinhão-manso possui alto teor de nutrientes em seus tecidos, apresentando a seguinte ordem de acúmulo no limbo foliar: $\mathrm{N}>\mathrm{Ca}>\mathrm{K}>\mathrm{Mg}$ $>\mathrm{P}>\mathrm{S}>\mathrm{Mn}>\mathrm{Fe}>\mathrm{B}>\mathrm{Zn}>\mathrm{Cu}$ (Laviola \& Dias, 2008). Estes autores constataram os valores de 3,$31 ; 15,85 ; 22,36$ e 5,61 mg/folha, para o conteúdo de P, K, Ca e Mg, respectivamente. Neste trabalho, os macronutrientes analisados nas folhas, no caule e nas raízes apresentaram ordem semelhante para o conteúdo, sendo $\mathrm{Ca}>\mathrm{K}>\mathrm{Mg}>\mathrm{P}$.

Apesar de o fósforo ser o quarto nutriente acumulado na matéria seca, ele é muito limitante para a cultura, sobretudo na fase inicial de crescimento. Resultados de pesquisas demonstram que o pinhão-manso em fase inicial de desenvolvimento é responsivo a adubação fosfatada (Prates et al., 2012).

Não houve efeito significativo do aumento da densidade do solo para os conteúdos de $\mathrm{Ca}$ e de $\mathrm{Mg}$ presentes nas folhas, no caule e nas raízes de pinhão-manso (Tabela 1).

Entretanto, Silva \& Rosolem (2001) verificaram que o aumento da densidade do solo de 1,12 para $1,36 \mathrm{~kg} \mathrm{dm}^{-3}$ reduziu o conteúdo de $\mathrm{Ca}$ e $\mathrm{Mg}$ para a cultura da soja. Neste trabalho, não se observou redução do conteúdo de $\mathrm{Ca}$ e $\mathrm{Mg}$ nas folhas, caule e raízes de pinhão-manso com o aumento da densidade do solo. Verificou-se que os teores de $\mathrm{Ca}$ e $\mathrm{Mg}$ no solo encontrava-se em altas concentrações (Tabela 1), assim, a interceptação radicular atendeu parte da demanda da planta e provavelmente o fluxo de massa supriu o restante da necessidade da cultura.

\section{CONCLUSÕES}

O aumento da densidade do solo de 1,08 a 1,64 $\mathrm{kg} \mathrm{dm}^{-3}$ prejudica o crescimento da parte aérea e das raízes do pinhãomanso na fase inicial de desenvolvimento da cultura.

A limitação do desenvolvimento da parte aérea ocorre a partir da densidade $1,26 \mathrm{~kg} \mathrm{dm}^{-3}$, com redução do número de folhas, da área foliar e da produção de matéria seca da parte aérea.
O aumento da densidade do solo afeta o conteúdo de $\mathrm{P}$ e K no tecido vegetal, elementos que são transportados no solo por difusão. Os teores $\mathrm{Ca}$ e $\mathrm{Mg}$ não são influenciados pelo aumento da densidade.

\section{REFERÊNCIAS}

Abreu HA, Guerra, GM, Mesquita, DN, Pereira, VC, Assis RL, Silva OA, Silva GP \& Imolesi AS (2006) Crescimento aéreo e radicular de pinhãomanso sob diferentes níveis de compactação do solo. In: $1^{\circ}$ Congresso da Rede Brasileira de Tecnologia de Biodiesel: artigos técnico-científico, Brasília. Anais, MCT/ABIPTI. p.144-149.

Alves VG, Andrade MJB, Corrêa JBD, Moraes AR \& Silva MV (2003) Concentração de macronutrientes na parte aérea do feijoeiro (Phaseolus vulgaris L.) em função da compactação e classes de solos. Ciência e Agrotecnologia, 27:44-53.

Araújo AP \& Machado CTT (2006) Fósforo. In: Fernandes MS (Ed.) Nutrição mineral de Plantas. Viçosa, Sociedade Brasileira de Ciência do Solo. p.253-280.

Arruda FP, Beltrão NEM, Andrade AP, Pereira WE \& Severino LS (2004) Cultivo de pinhão manso (Jatropha curcas L.) como alternativa para o semi-árido nordestino. Revista Brasileira de Oleaginosas e Fibrosas, 8:789-799.

Beltrão NEM (2005) Agronegócio das oleaginosas no Brasil. Informe Agropecuário, 26:44-78.

Bonfim-Silva EM, Anicésio ECA, Silva FCM, Dourado LGA \& Aguero NF (2011) Compactação do solo na cultura do trigo em Latossolo do Cerrado. Disponível em: <http://www.conhecer.org.br/enciclop/ 2011a/agrarias/compactacao.pdf $>$. Acessado em: 30 de janeiro de 2012.

Braga JM \& Defelipo BV (1974) Determinação espectrofotométrica de fósforo em extratos de solo e plantas. Revista Ceres, 21:73-85.

Castro CM, Devide ACP \& Camargo CA (2011) Efeito do espaçamento no desenvolvimento do pinhão manso em sistema de integração com pecuária de corte. In: Congresso da Rede Brasileira de Tecnologia de Biodiesel e Congresso Brasileiro de Plantas Oleaginosas, Óleos, Gorduras e Biodiesel, Belo Horizonte. Disponível em: <http:// www.aptaregional.sp.gov.br>. Acessado em: 20 de dezembro de 2013.

Costa FX, Nunes Júnior ES \& Melo Filho JS (2010) Efeito da torta de mamona no plantio da mamoneira com diferente densidade global do solo. Revista Engenharia Ambiental: pesquisa e tecnologia, 7:229-238.

Costa JPV, Barros NF, Bastos AL \& Albuquerque AW (2009) Fluxo difusivo de potássio em solos sob diferentes níveis de umidade e de compactação. Revista Brasileira de Engenharia Agrícola Ambiental,13:56-62.

Dias LAS, Leme LP, Laviola BG, Pallini Filho A, Pereira OL, Carvalho M, Manfio CE, Santos AS, Sousa LCA, Oliveira TS \& Dias DCFS (2007) Cultivo de pinhão-manso (Jatropha curcas L.) para produção de óleo combustível. Viçosa, MG. 40p.

EMBRAPA - Empresa Brasileira de Pesquisa Agropecuária (2006) Sistema Brasileiro de Classificação de Solos. Rio de Janeiro, Embrapa. 412p

EMBRAPA - Empresa Brasileira de Pesquisa Agropecuária (1997) Manual de métodos de análise de solo. $2^{\mathrm{a}}$ ed. Rio de Janeiro, Embrapa. 212p.

Ferreira DF (2000) Análise estatística por meio do SISVAR (Sistema para Análise de Variância) para Windows versão 4.0. In: Reunião Anual da Região Brasileira da Sociedade Internacional de Biometria, São Carlos. Anais, UFSCar. p.255-258.

Laviola BG \& Dias LAS (2008) Teor e acúmulo de nutrientes em folhas e frutos de pinhão manso. Revista Brasileira de Ciência do Solo, 32:1969-1975. 
Mapfumo E, Chanasyk DS, Naeth MA \& Baron VS (1998) Forage growth and yield components as influenced by subsurface compaction. Agronomy Journal, 90:805-812.

Materechera SA, Alston AM, Kirby JM \& Dexter AR (1992) Influence of root diameter on the penetration of seminal roots into a compacted subsoil. Plant and Soil, 144:297-303.

Medeiros RD, Soares AA \& Guimarães RM (2005) Compactação do solo e manejo da água. I: Efeitos sobre a absorção de N, P, K, massa seca de raízes e parte aérea de plantas de arroz. Ciência e Agrotecnologia, 29:940-947.

Meurer EJ (2007) Fatores que influenciam a crescimento e desenvolvimento das plantas. In: Novais RF, Alvarez VH, Barros NF, Fontes RLF, Cantarutti R B \& Neves J CL (Eds). Fertilidade do solo. Viçosa, Sociedade Brasileira de Ciência do Solo. p.65-90.

Meurer EJ (2006) Potássio. In: Fernandes MS (ed.) Nutrição mineral de Plantas. Viçosa, Sociedade Brasileira de Ciência do Solo. p.281-298.

Müller MAL, Ceccon G \& Rosolem CA (2001) Influência da compactação do solo em subsuperfície sobre o crescimento aéreo e radicular de plantas de adubação verde de inverno. Revista Brasileira de Ciência do Solo, 25:531-538.

Novais RF \& Smyth TJ (1999) Fósforo em solo e planta em condições tropicais. Viçosa, UFV. 399p.

Nunes LF (2007) Caracterização de frutos, sementes e plântulas e cultivo de embriões de pinhão-manso (Jatropha curcas L.). Dissertação de Mestrado. Universidade Federal de Lavras, Lavras. 78p.

Prates FBS, Lucas CSG, Sampaio RA, Brandão Júnior DS, Fernandes LA \& Zuba Junior RGR (2012) Crescimento de mudas de pinhão-manso em resposta a adubação com superfosfato simples e pó-de-rocha. Revista Ciência Agronômica, 43:207-213.

Raij BV (2011) Fertilidade do solo e manejo de nutrientes. Piracicaba, International Plant Nutrition Institute. 420p.

Ribeiro MAV, Novais RF, Faquin V, Ferreira MM, Furtini Neto AE, Lima JM \& Villani EMA (2010) Resposta da soja e do eucalipto ao aumento da densidade do solo e a doses de fósforo. Revista Brasileira de Ciência do Solo, 54:1187-1164.

Saturnino HM, Pacheco DD, Kakida J, Tominaga N \& Gonçalves NP (2005) Cultura do Pinhão Manso (Jatropha curcas L.). Informe Agropecuário, 26:44-78.
Secco D, Reinert DJ, Reichert JM \& Ros CO (2004) Produtividade de soja e propriedades físicas de um Latossolo submetido a sistemas de manejo e compactação. Revista Brasileira de Ciência do Solo, 28:797-804.

Silva GP, Novais RF, Neves JCL \& Barros NF (1992) Respostas de espécies de gramíneas forrageiras a camadas compactadas de solo. Revista Ceres, 39:31-43.

Silva RH \& Rosolem CA (2001) Influência da cultura anterior e da compactação do solo na absorção de macronutrientes em soja. Pesquisa agropecuária brasileira, 36:1269-1275.

Silva SD, Alves JM, Mesquita GM \& Leandro WM (2012) Efeito da compactação do solo no desenvolvimento aéreo e radicular do pinhão manso (Jatropha curcas L.) e crambe (Crambe abyssinica Hochst). Global Science and Technology, 05:87-97.

Silva SR, Barros NF, Novais RF \& Pereira PRG (2002) Eficiência nutricional de potássio e crescimento de eucalipto influenciados pela compactação do solo. Revista Brasileira de Ciência do Solo, 26:1001-1010.

Silva SR (2000) Crescimento do eucalipto influenciado pela compactação de solos e doses de fósforo e de potássio. Dissertação de mestrado. Universidade Federal de Viçosa, Viçosa. 97p.

Silva VR, Reinert D \& Reichert JM (2004) Variabilidade espacial da resistência à penetração em plantio direto. Revista Ciência Rural, 34:399406.

Stolf R (1991) Teoria e teste experimental de fórmulas de transformação dos dados de penetrômetro de impacto em resistência do solo. Revista Brasileira de Ciência do Solo, 15:229-235.

Suzuki LEAS, Reichert JM, Reinert DJ \& Lima CLR (2007) Grau de compactação, propriedades físicas e rendimento de culturas em Latossolo e Argissolo. Pesquisa Agropecuária Brasileira, 42:11591167.

Tavares Filho J, Ralisch R, Guimarães MF, Medina CC, Balbino LC \& Neves CSVJ (1999) Método do perfil cultural para avaliação do estado físico de solos em condições tropicais. Revista Brasileira de Ciência do Solo, 23:393-399.

Vale LS, Severino LS \& Beltrão NEM (2006) Crescimento do pinhão manso em solo compactado. Disponível em: <http:// www.biodiesel.gov.br/docs/congresso2006/agricultura/ CrescimentoPinhao.pdf>. Acessado em: 29 de fevereiro de 2012. 